\title{
Research
}

\section{Management of depression and referral of older people to psychological therapies:}

\author{
a systematic review of qualitative studies
}

\begin{abstract}
Background

Depressive symptoms are common in later life and increase both the risk of functional and cognitive decline and the use of healthcare services. Despite older people expressing preferences for talking therapies, they are less likely to be referred than younger adults, particularly when aged $\geq 80$ years.

Aim

To explore how healthcare professionals (HCPs) manage older people in relation to depression and referrals to psychological therapies.
\end{abstract}

\section{Design and setting}

Systematic review and thematic synthesis of qualitative studies.

\section{Method}

MEDLINE, Embase, PsycINFO, CINAHL, and the Social Sciences Citation Index (inceptionMarch 2018) were searched for studies exploring HCPs' views regarding management of late-life depression across all settings. Studies of older people's views or depression management across all ages were excluded.

\section{Results}

In total, 27 studies, were included; these predominantly focused on the views of GPs and primary and community care nurses. Many HCPs felt that late-life depression was mainly attributable to social isolation and functional decline, but treatments appropriate for this were limited. Clinicians perceived depression to have associated stigma for older adults, which required time to negotiate. Limited time in consultations and the complexity of needs in later life meant physical health was often prioritised over mental health, particularly in people with frailty. Good management of latelife depression appeared to depend more on the skills and interest of individual GPs and nurses than on any structured approach.

\section{Conclusion}

Mental ill health needs to be a more-prominent concern in the care of older adults, with greater provision of psychological services tailored to later life. This may facilitate future identification and management of depression.

\section{Keywords}

aged; depression; frail elderly; primary health care; qualitative research; review.

\section{INTRODUCTION}

Late-life depression is highly prevalent and estimates suggest $4.6-9.3 \%$ of adults aged $\geq 75$ years have major depressive disorder and up to $37.4 \%$ have subthreshold depressive symptoms.' Depressive symptoms are associated with poorer quality of life, increased mortality risk, cognitive and functional decline, and greater utilisation of health services. ${ }^{2-4}$ Between 2014 and 2039, the number of people in the UK aged $>60$ years is projected to increase from 14.9 million to 21.9 million, and so appropriate management of latelife depression will become increasingly important.

Late-life depression is often managed in primary care, ${ }^{6}$ with $87.1 \%$ prescribed an antidepressant. ${ }^{7}$ Antidepressants have some limitations: increased age is associated with reduced efficacy ${ }^{8}$ and potential adverse effects, and their use has not been comprehensively studied in very old age groups (for example, people aged $\geq 85$ years), people with serious medical comorbidities, or those with poor nutritional status. ${ }^{9,10}$ Older adults generally report a preference for talking therapies, especially for low-level symptoms, and a willingness to talk to mental health providers about their emotional health. ${ }^{11-14}$ However, in the UK older adults' access to Improving Access to Psychological Therapies (IAPT) services is low, 15,16 despite their effectiveness. ${ }^{17}$

R Frost, MSc, PhD, research associate; C Bhanu, MB BChir, academic clinical fellow; K Walters, MSc, PhD, MMed, MRCGP, professor of primary care \& epidemiology and director of Centre for Ageing Population Studies, Department of Primary Care and Population Health, University College London, London. A Beattie, PhD, RGN C.Psychol, research fellow; Y Ben-Shlomo, MSc, $\mathrm{PhD}, \mathrm{MRCP}$, professor of clinical epidemiology, Population Health Sciences, University of Bristol, Bristol.

Address for correspondence

Rachael Frost, Department of Primary Care and
Recorded referrals are as low as 3.5\% and this inequality increases with greater age: those aged $\geq 85$ years are five times less likely to be referred for psychological therapies as those aged 55-59 years, and one-third more likely to be prescribed an antidepressant.?

Qualitative studies can offer insights into reasons for these low referral rates ${ }^{18,19}$ and two previous meta-syntheses ${ }^{20,21}$ explored depression management in the general adult population. However these did not comprehensively explore differences in management due to age. Therefore, the aim of this systematic review was to scope the qualitative literature to investigate how healthcare professionals (HCPs) manage older people in relation to depression, particularly regarding referrals to psychological therapies.

\section{METHOD}

The study team comprised a health services researcher, two academic GPs, a clinical epidemiologist/public health specialist, and an academic nurse. A thematic synthesis approach was used from a constructivist perspective. This aimed to produce outputs directly relevant to policymakers and practitioners, and allows reviewers to look for differences in perspectives according to study characteristics, such as type of HCP. ${ }^{22,23}$ The protocol was registered on PROSPERO (reference: 42017055207).

Population Health, University College London, Royal Free Campus, Rowland Hill Street, London NW3 2PF, UK

Email: rachael.frostaucl.ac.uk

Submitted: 17 July 2018; Editor's response: 21 August 2018; final acceptance: 7 September 2018.

\section{British Journal of General Practice}

This is the full-length article (published online 12 Feb 2019) of an abridged version published in print. Cite this version as: Br J Gen Pract 2019; DOI: https://doi.org/10.3399/bjgp19X701297 


\section{How this fits in}

Older people are often prescribed antidepressants and are less likely than younger adults to be referred to psychological therapies, particularly when they are aged $\geq 80$ years. Qualitative research was synthesised to understand how healthcare professionals (HCPs) manage late-life depression, particularly regarding psychological therapy referrals. It was found that clinicians had little time to negotiate the complex issue of depression and so prioritised physical over mental health needs in older people. HCPs reported a lack of treatments that were both available and appropriate, and so management depended on the individual practitioners' skills rather than a coherent structure.

MEDLINE (1946-March 2018), Embase (1974-March 2018), PsycINFO (1806March 2018), CINAHL (1937-March 2018), and the Science Social Sciences Citation Index (SSCI) (1900-March 2018) databases were searched (database search terms are available from the authors on request). Grey literature was identified through searches of the e-theses online service (EThOS) (inception-April 2018). Studies were eligible for inclusion if:

- most participants were primary or secondary HCPs;

- qualitative methods were used to collect and analyse data in a substantial part of the study; and

- they featured views and experiences of the treatment and management of older people with depression.

\section{Studies were excluded if they:}

- focused on depression management in younger/all age groups or in people with a specific medical condition, for example, post stroke;

- explored the effects or implementation of new interventions;

- studied later-life mental health without specific depression data;

- included views of social services, thirdsector, or trainee staff only;

- focused on pharmacotherapy or suicide only;

- were quantitative or non-empirical; or

- were published in a language other than English (these were excluded due to a lack of translation facilities).
Two reviewers independently assessed $10 \%$ of the titles and abstracts $188 \%$ agreement, with disagreements resolved through discussion), and a further $10 \%(91 \%$ agreement). Each reviewer then screened half of the remaining records. Full texts were appraised independently by the same two reviewers, with disagreements resolved through discussion or consultation with the whole team.

\section{Data extraction and synthesis}

Data relating to study aims, location, participants, data collection, analysis, themes, and authors main implications were extracted by one reviewer and papers were imported into NVivo (version 12) for synthesis. Study quality was appraised using seven questions derived from the Critical Appraisal Skills Programme checklist and other checklists. ${ }^{24-26}$ Two reviewers independently assessed study quality according to individual items and gave an overall subjective judgement of:

- quality (very poor, poor, not very good, good, very good, excellent); and

- reporting quality (poor, acceptable, good).

Quality was assessed to provide an overall summary of the evidence base, but studies were not excluded and findings were not weighted within the synthesis on the basis of quality; this was because the role of quality assessment within qualitative systematic reviews has a number of associated debates, as highlighted by Dixon-Woods et al. ${ }^{26}$

A thematic synthesis approach was followed, which comprised coding text, developing descriptive themes, and 'going beyond' the primary studies to develop analytical themes and answer the questions posed by the review, in line with recommendations by Thomas et al. ${ }^{22}$ Results sections of included papers were coded line by line by one reviewer, with independent analysis of one-third of the papers undertaken by another. These codes were aggregated to create descriptive themes that were summarised and discussed by all authors (the framework is available from the authors on request).

In order to go 'beyond' the data, analytical themes were developed by one reviewer. Potential connections and groupings were modelled, with statements written out hypothesising links, connections, and themes. These were compared with coded data within and across studies and HCPs, and refined until subthemes and themes were constructed. The analytical themes 
were reviewed by all authors, refined, and then agreed on.

\section{RESULTS}

Out of 1471 unique records, 161 full texts were screened and 27 studies were included in the qualitative synthesis ( $n=2$ arising from the same dataset) (Figure 1). The majority of studies were carried out in Western countries leight in the UK, eight in the US, five in Australasia, three in Scandinavia, and one in Canada), plus one each in Taiwan and India (Table 1); detailed study summaries are available from the authors on request. Studies reflected both publicly funded and insurance-based systems. Qualitative data were mostly collected via interviews ${ }^{18,19,27-42}$ and/or focus groups $34,39,43-46$ with two ethnographic studies, ${ }^{47,48}$ one conference and nominal group technique, ${ }^{49}$ one mixedmethods survey, ${ }^{50}$ and one multiple case study. ${ }^{51}$ Two-thirds of studies were of good/ very good overall quality (Table 1); most met

Figure 1. Flow chart of search and apprais process. $\mathrm{HCP}=$ healthcare professional. the checklist criteria and the vast majority were well reported (Table 2).

Most HCPs were sampled from primary and community healthcare (for example GPs, practice nurses, or home health nurses), $18,19,28,29,31,32,34,39-42,44,47,48,50$ with six studies sampling both primary and secondary care professionals, ${ }^{27,35,45,46,49,51}$ and a small number studying HCPs in care settings..$^{33,38,43}$ One study sampled community psychiatric nurses (CPNs) ${ }^{36}$ and one included practice counsellors. ${ }^{18}$ As similar groups of professionals were often referred to with different names in different countries, each professional was grouped under a UK heading (for example, GPs for primary care physicians) in the thematic synthesis.

Five themes relating to management were identified:

- avoidance of medicalisation of social circumstances;

- assumptions regarding older people and mental health;

- prioritisation of physical health across healthcare settings;

- the 'postcode lottery' of therapeutic options; and

- variation in skills, training, and approaches across all settings.

\section{Avoidance of medicalisation of social circumstances}

Late-life depression was felt to lack suitable therapeutic solutions as it was considered to mainly arise from 'justifiable' causes, many of which related to ageing. The majority of HCPs across all countries primarily attributed late-life depression to difficult social circumstances and, in particular, age-related social issues (for example, loneliness or bereavements) and/or physical health issues, frailty, and functional decline: 18,19,32-34,37,39-44,51

'GPs described depression as part of a spectrum including loneliness, lack of social network, reduction in function, and very much saw depression as "understandable" and "justifiable".'19

Many GPs and nurses, therefore, felt there was a definite difference between sadness or distress that 'understandably' related to these issues, and clinical depression, but rarely defined where this border lay. ${ }^{18,19,31,32,39,43}$ Consequently, across all studies discussing this issue, there was a clear tension as to whether medical treatment Iparticularly 
Table 1. Study characteristics.

\begin{tabular}{|c|c|c|c|c|}
\hline Study & Country & Healthcare professionals & Data collection method & Quality rating \\
\hline Aakhus, et al (2014) $)^{35}$ & Norway & $\begin{array}{l}\text { GPs, nurses (primary and secondary health care), psychiatrists, } \\
\text { researchers ( } n=26 \text { total) }\end{array}$ & Interviews & Not very good \\
\hline $\begin{array}{l}\text { Apesoa-Varano, et al } \\
(2010)^{28}\end{array}$ & US & $\begin{array}{l}\text { Primary care physicians ( } n=9) \text {, depression care managers } \\
\text { ( } n=9 \text { nurses, } n=2 \text { psychologists) }\end{array}$ & Interviews & Very good \\
\hline Bao, et al $(2014)^{30}$ & US & Nurses ( $n=9)$, nurse supervisors ( $n=5)$, clinical/medical directors $(n=6)$ & Interviews & Good \\
\hline Bao, et al (2015) $)^{29}$ & US & Nurses ( $n=9)$, nurse supervisors ( $n=5)$, clinical/medical directors ( $n=6)$ & Interviews & Not very good \\
\hline Burroughs, et al (2006) $)^{19}$ & UK & $\begin{array}{l}\text { GPs }(n=9) \text {, practice nurses }(n=3) \text {, district nurses }(n=2) \text {, } \\
\text { community nurses ( } n=3)\end{array}$ & Interviews & Very good \\
\hline Dickinson, et al (2010) $)^{31}$ & UK & $\operatorname{GPs}(n=10)$ & Interviews & Good \\
\hline Gordon $(2013)^{32}$ & UK & GPs $(n=14)$ & Interviews & Very good \\
\hline Hassall and Gill (2008) $)^{33}$ & Australia & $\begin{array}{l}\text { Care staff ( } n=17 \text { ), including directors of nursing, clinical nurse } \\
\text { consultants, registered nurses, respite coordinators, and social workers }\end{array}$ & Interviews & Good \\
\hline Iden, et al (2011) $)^{43}$ & Norway & Full- and part-time nursing home doctors ( $n=16)$, registered nurses $(n=8)$ & Three focus groups & Good \\
\hline Liebel and Powers (2015) $)^{34}$ & US & Home healthcare nurses ( $n=16)$ & $\begin{array}{l}\text { Individual interviews and } \\
\text { two focus groups }\end{array}$ & Very good \\
\hline Liebel, et al (2015) $)^{47}$ & US & Home healthcare nurses $(n=4)$ & $\begin{array}{l}\text { Observation of } 25 \text { home visits, } \\
\text { with moderate participation }\end{array}$ & Very good \\
\hline $\operatorname{Lin}(2005)^{36}$ & US & Psychiatric home care nurses $(n=9)$, team director $(n=1)$ & Interviews & Not very good \\
\hline Lu and Hsieh $(2013)^{37}$ & Taiwan & $\begin{array}{l}\text { Public health nurses ( } n=12) \text {, home care nurses }(n=5) \text {, long-term } \\
\text { care nurses }(n=2) \text {, social workers }(n=5) \text {, dietitian }(n=1)\end{array}$ & Interviews & Very good \\
\hline McCabe, et al (2009)38 & Australia & $\begin{array}{l}\text { Professional care assistants from different aged settings ( } n=21) \text {, } \\
\text { registered nurses ( } n=2) \text {, trainee nurses ( } n=2), \operatorname{GPs}(n=10), \\
\text { senior aged care managers }(n=7)\end{array}$ & Interviews & Not very good \\
\hline Murray, et al (2006) $)^{18}$ & UK & GPs $(n=18)$, practice nurses ( $n=7)$, practice counsellors $(n=5)$ & Interviews & Very good \\
\hline Patel and Prince $(2001)^{44}$ & India & Primary health centre doctors ( $n=3)$, multipurpose health workers ( $n=17)$ & $\begin{array}{l}\text { Three focus groups, including } \\
\text { a vignette on depression }\end{array}$ & Not very good \\
\hline Pusey $(2009)^{39}$ & UK & District nurses $(n=11)$ & $\begin{array}{l}\text { Three focus groups, one } \\
\text { individual interview }\end{array}$ & Very good \\
\hline $\begin{array}{l}\text { Saarela and } \\
\text { Engeström }(2003)^{45}\end{array}$ & Finland & Primary care physicians ( $n=25)$, psychiatrists ( $n=11$ ) & $\begin{array}{l}\text { Seven focus groups and } \\
\text { individual management } \\
\text { plans, using two vignettes }\end{array}$ & Not very good \\
\hline Stanners, et al (2012) $)^{40}$ & Australia & GPs $(n=8)$ & Interviews & Very good \\
\hline Strachan, et al (2015) $)^{41}$ & UK & GPs $(n=9)$ & Three group interviews & Good \\
\hline Sussman, et al (2011) $)^{49}$ & Canada & $\begin{array}{l}\text { Family physicians }(n=3) \text {, psychiatrists }(n=2) \text {, nurse practitioners }(n=3) \text {, } \\
\text { social workers }(n=3) \text {, decision makers }(n=1)\end{array}$ & $\begin{array}{l}\text { Small group discussions, } \\
\text { with nominal group technique } \\
\text { ranking of proposed solutions }\end{array}$ & Good \\
\hline Tai-Seale, et al (2007) ${ }^{48}$ & US & Physicians ( $n=35$ ) & $\begin{array}{l}\text { Observations of } 385 \text { videotaped } \\
\text { consultations between } \\
\text { physicians and older people }\end{array}$ & Not very good \\
\hline Todman, et al $(2011)^{50}$ & UK & GPs ( $n=119)$ & $\begin{array}{l}\text { Mixed methods questionnaire } \\
\text { survey including an open } \\
\text { qualitative question }\end{array}$ & Not very good \\
\hline Timson $(2013)^{51}$ & UK & $\begin{array}{l}\text { Referring agents (GPs, } n=4 \text { ), referred-to psychologists ( } n=4) \text {, wider } \\
\text { members of case groups ( } n=13 \text {, including older adults, family member, } \\
\text { community psychiatric nurse, and, sometimes, a psychiatrist) }\end{array}$ & $\begin{array}{l}\text { Multiple case study of four older } \\
\text { adults with depression and } \\
\text { professionals around them }\end{array}$ & Good \\
\hline Waterworth, et al (2015) 42 & NZ & $\begin{array}{l}\text { Primary health care nurses, district nurses, heart failure nurses } \\
\text { ( } n \text { not reported) }\end{array}$ & Interviews & Not very good \\
\hline White, et al (2017) ${ }^{46}$ & Australia & $\begin{array}{l}\text { HCPs from acute settings ( } n=7 \text { ), sub-acute (geriatric assessment } \\
\text { and rehabilitation, } n=20 \text { ) and community care ( } n=27) \text {, including } \\
\text { medical officers, physiotherapists, occupational therapists, social } \\
\text { workers, neuropsychologists, registered nurses, podiatrists, speech } \\
\text { pathologists, and music therapists }\end{array}$ & Eleven focus groups & Very good \\
\hline Wittink, et al (2011) & US & $\begin{array}{l}\text { Internists (internal medicine physicians, with focus on adult medicine, } \\
n=9 \text { ), family doctors ( } n=4 \text { ), geriatric medicine physicians ( } n=2 \text { ) }\end{array}$ & Interviews & Very good \\
\hline
\end{tabular}

$\mathrm{HCP}=$ healthcare professional. $\mathrm{NZ}=$ New Zealand. 


\section{Table 2. Quality appraisal for included research papers, $n=27$}

\begin{tabular}{|c|c|c|}
\hline Quality appraisal question & Yes, $n(\%)$ & No, $n(\%)$ \\
\hline Does the research involve qualitative methods of data collection and analysis? & $27(100)$ & $0(0)$ \\
\hline Does the research have clear aims and objectives? & $26(96)$ & $1(4)$ \\
\hline Were the data collected in a way that addressed the research aim? & 23 (85) & $4(15)$ \\
\hline Was the data analysis sufficiently rigorous to address the aims of the research? & $23(85)$ & $4(15)$ \\
\hline Can one be confident that all the relevant data were taken into account? & $22(81)$ & $5(19)$ \\
\hline Were sufficient data presented to support the interpretations made? & $20(74)$ & $7(26)$ \\
\hline $\begin{array}{l}\text { Did the study demonstrate theoretical insight, novel findings, or } \\
\text { novel perspectives? }\end{array}$ & $27(100)$ & $0(0)$ \\
\hline \multirow{3}{*}{ What was the quality of the reporting methods? } & Acceptable & Poor \\
\hline & $7(26)$ & $2(7)$ \\
\hline & Good & Not very good \\
\hline Overall quality assessment & $7(26)$ & 9 (33) \\
\hline
\end{tabular}

antidepressants) could be beneficial or represented a medicalisation of social issues. This was further complicated by widespread views from GPs and nurses that addressing depression in some way was essential: $18,19,27,31,32,39-41,43$

GPS tended to acknowledge social and emotional causes that required non-drug interventions they could not always provide and, although antidepressants offered a solution to some patient's problems, there appeared to be sense of unease about prescribing a medical intervention for a social cause. ${ }^{31}$

'Social solutions'41 (for example, day centres) were considered the mostappropriate approach; ${ }^{19,34,35,39,41,44,45}$ however although these addressed the perceived cause, they were not always regarded as effective, leading to therapeutic pessimism:

"a man who is clearly isolated ... taking him out to the day centre, that'll be good for him won't it, sit in a room with other demented, depressed people, and make your mood lift. It's not gonna happen." IG3, psychologist) ${ }^{51}$

When depression was conceptualised as a response to physical illness and/ or disability, 18,19,32-34,37,40-42,51 even fewer solutions were identified, with the person's future regarded as negative. ${ }^{51}$ Physical health problems were deemed to be a barrier to psychological treatments by psychologists and $\mathrm{CPNs}^{36,51}$ and psychological approaches were seen as inappropriate by some GPs. ${ }^{41}$ "usually because they're bloody sick, and is a psychologist going to help that? I don't think so." (D6)" 40

A minority of home care nurses and GPs reported using clinician support to encourage adaptation to disability; ${ }^{32,34}$ otherwise, in response to disability, medicalisation land subsequent antidepressant prescribing) was seen as a better alternative to doing nothing. ${ }^{31,40}$

\section{Assumptions regarding older people and mental health}

HCPs held a number of assumptions regarding older people's attitudes to depression; the most pervasive was that older people normalised depression as part of ageing, isolation, and decline, and felt it to be stigmatising. $18,19,31,34,37,38,40-42,46,51$ Few discussed the idea that older people may have had early or mid-life experiences of depression. HCPs, consequently, assumed that late-life depression was likely to be hidden; that older people were resistant to articulating depression or distress, instead 'sprucing up' for the GP or presenting somatically: $27,28,31-34,37,39-42,49,51$

Older people were reported to attribute symptoms differently, and to have more rigid and strongly held beliefs about stigma, the desirability of coping unsupported, and the implications of failure to do so. ${ }^{41}$

GPs and district nurses, therefore, felt that depression took time, effort, and skill to actively look for by indirectly focusing on symptoms and related concepts such as loneliness or homesickness, using screening tools, or medicalising language (for example, 'clinical depression' or 'neurobiology'] to reduce stigma. ${ }^{19,27,30,32,37}$

This assumption of stigma and 'hidden' depression did not translate to home and residential care settings. Observational and HCP-reported data suggested overt symptoms, such as crying, poor selfcare, and reporting feeling sad, $33,39,47$ were displayed, although this did not increase the likelihood of treatment:

[observation] A patient says "I'm feeling sad today, "while the nurse comments on a blood pressure reading. '47

Although individual treatment preference was considered more important than age in some studies, $32,34,39$ there were widespread assumptions that older adults disliked, and were reluctant to engage with, any mental 
health-related treatment. Psychiatry was considered particularly stigmatised, and so psychiatry referrals were a last resort: ${ }^{4}$

Attaching depression to mental illness was also reported as a barrier to older adults seeking mental healthcare services [...] "They will not accept seeing a psychiatrist because, in general, people believe that psychiatry is for treating crazy people". 37

Decision-making power in late-life depression rested chiefly with professionals. Some HCPs (mainly GPs) assumed that older adults were uninterested in talking therapies or that they would be ineffective, 19,31,32,35,37,46 particularly if they were computer based (such as online cognitive behavioural therapy), ${ }^{42}$ and so were likely to dismiss these as an option. ${ }^{35}$ This did not always preclude referrals if other treatments were ineffective, but ageist stereotypes were also evident in psychological therapists and CPNs, who felt that older people were unwilling to change - ' $\ldots$... it would not be obvious to me at 76 what would improve. (G3, psychologist) ${ }^{5} 51$ - and discharged themselves more quickly. ${ }^{36,51}$

Some HCPs felt that older adults conceptualised antidepressants as having a stigma or being addictive, and so required persuasion to take them. ${ }^{28,31,37,40}$ Despite GPs feeling they had greater influence on older, as opposed to younger, people, ${ }^{34,41}$ their assumptions that older people were resistant meant they felt that it was easier to circumvent depression during treatment by prescribing antidepressants for 'insomnia' or 'pain', or using GP support: ${ }^{32,37}$

I would say that even seeing someone and talking a bit in the GP surgery is a treatment in a sense although they might not think of it like that, they might just think it's a chat. (GP9, p3)'32

\section{Prioritising physical health across healthcare settings}

Implicitly and explicitly, physical health issues were prioritised over mental health. 19,27,28,32-37,39,41,42,46,47,51 Severe depressive symptoms could prompt action, but severity was usually defined in terms of physical impact (for example, suicidal ideation, impact on discharge planning. . $4,41,46$ The subject of depression was, therefore, sometimes avoided completely, despite some recognition that physical and mental health interacted: $32,34,45$

[observation] A patient says "I just want to die," and the nurse nods head without verbal response and asks if the patient has had a recurrence of a bothersome physical symptom". 47

This was also affected by organisational time pressures: non-psychiatric secondary care was considered a poor place for depression management, due to multiple assessments from varied professionals, the acute focus, and the lack of an identified responsible person and follow-up. ${ }^{46}$ The widespread view that late-life depression was best managed in primary care in many UK, Australian, US, and Taiwanese studies, ${ }^{19,37,39-41,46}$ with mental health services as consultative support, ${ }^{41}$ was, however, at odds with the time available to GPs:

'[They are] commonly complaining of not having enough time to address the many complex issues surrounding depression in later life. "In 10 minutes there is a lack of time as to what you can do with somebody ... sometimes you don't get to the nitty gritty."(GP5, p4)'32

In the US, home nursing visits were only eligible for insurance reimbursement if the older person had a documented need for physical health care, ${ }^{34,36}$ while UK district nurses' time was limited more implicitly. ${ }^{40}$ Mental health was viewed by many HCPs as outside of their role, which was reflected in their lack of mental health training. ${ }^{19,29,32-34,39,40}$ In this case, mental health was addressed only if they had time or could do so outside of appointments; for example, GPs with extended consultation times $^{32}$ or home care nurses scheduling evening appointments: ${ }^{34,37,39}$

'The district nurses described strategies to provide the time they felt people needed but they were unable to provide as an accepted part of their role. This involved logistical approaches such as leaving certain visits until the end of the day or scheduling a visit at weekends. ${ }^{39}$

Addressing psychological issues as a key part of physical health care for a condition (for example, cancer) was viewed as more accessible for older people. ${ }^{42}$ Some GPs justified a physical focus as older people were at higher risk of illnesses such as dementia or cancer, which could have a similar presentation. ${ }^{32,37}$ However, many felt that, despite the commonality of depression in people who are frail and housebound across primary, community, and acute 
settings, it was much more likely to be overlooked:31,32,41,46

'Paradoxically, as old age and ill health became more integrally associated with depression and its treatment, the latter was less often mentioned in consultations. ${ }^{31}$

Conversely to this prioritisation of physical health, across the studies, few concerns were expressed regarding how antidepressants might impact on physical health issues (for example, increased falls risk). ${ }^{19,40}$ A sense of therapeutic inertia seemed to occur once patients who were frail were taking antidepressants as clinicians feared upsetting a delicate equilibrium or giving rise to care problems. . $^{31,33,43}$

\section{The 'postcode lottery' of therapeutic options}

Although psychological therapies, psychiatric services, social workers, or social activities were considered appropriate to the perceived causes of late-life depression, they were constrained by wide differences in provision across localities. ${ }^{19,28,31-35,37,39-42,44,46,48,50}$ Long waiting times, narrow eligibility criteria, poor integration with other care, being inappropriate to needs or preferences, financial constraints, and limited duration of support were key issues. ${ }^{31,34,39-41,43,46,50}$ This led to an automatic discounting of psychological therapies or social approaches as an option:

'“'You've got to be pretty sick or mad to get any extra help ..." (PN1)"19

As GPs and nurses felt that depression did need to be addressed when raised, having solutions that were both appropriate and available led to a greater inclination to identify late-life depression, regardless of other factors; particularly if HCPs were less confident about managing it themselves. However, the reverse was true when services were not available: 19,32,42

'The majority of healthcare professionals described a reluctance to make the diagnosis of depression in an elderly person because of a feeling that they had nothing to offer the patient.' 19

When nothing else could be offered, GPs and community nurses tended to provide support themselves to the older person in various ways or prescribe antidepressants. ${ }^{31,43}$ Limited referral options were not always related solely to provision, however, some clinicians reported needing further local service knowledge. $33,46,49$

Variation in skills, training, and approaches across all settings

Differences in HCPs' skills, interest, and perceived role in depression management were reported across all settings. Those with greater confidence in managing depression (usually GPs) were more likely to raise the topic. 19,30,32,34,40-42,45 Confidence related to training and experience, something for which non-psychiatric nurses and acute care professionals expressed a need. 19,29,34,35,39,42,46

Personal interest also influenced individual GP approaches, for which a number of studies developed typologies. ${ }^{28,32,48}$ For many GPs, active listening and using the therapeutic relationship to change views about depression was seen as an effective and sufficient treatment strategy, especially for mild symptoms, 19,32,37,39-41,44,45,48 and so they were reluctant to refer on. The minority who felt insufficiently trained to offer this, ${ }^{19,41}$ or felt that their remit was only to refer on or prescribe medication, $28,32,51$ were more likely to refer when these services were available.

Different approaches and attitudes had clear effects on patients' and teams' experiences:

Residential aged care services that had positive experiences with GPS found the referral process to other external services for depression and subsequent outcomes for residents far more positive and beneficial. On the other hand, an equal number of participants expressed disappointment at the services provided by GPS. ${ }^{33}$

Some nurses felt confident they had a role in depression identification and management by reporting concerns to the GP and coaching patients on broaching depression, 27,30 emotionally connecting with patients, ${ }^{47}$ referring to local services, ${ }^{33}$ or counselling regarding physical loss and disability. ${ }^{28}$ However, some nurses and many GPs felt it was outside of the nurse's role and that these HCPs lacked skills and/ or training to manage it: $19,29,33,39,42,43$

Nurse: "We are not skilled in differentiating between these conditions. If they cry, we call it depression and give them antidepressants. And that's it". "43

Interprofessional communication played a key role in home nursing and residential care settings. $28,37,39,42,43,47$ The greater number of communication channels required to refer to primary care and the 
associated hierarchical issues meant that concerns could be lost or dismissed, even if depression was adequately identified. 33,38,39,43

Other relevant professionals were thought to include social workers IUS and Australia),,27.46 psychiatrists, ${ }^{45}$ and multipurpose community health workers (India). ${ }^{44}$ Psychologists and psychiatrists were considered skilled in late-life depression management, but little further information regarding psychiatrists' views was found. Nevertheless, strong mental health service collaborations were considered important and increased other HCPs confidence in managing depression; these collaborations appeared to be incidental, however, arising from interested individuals rather than a clear structure: $32,41,42,49$

... most participants emphasised that their best collaborations evolved on a case by case basis as they found health professionals on mental health teams with whom they could readily consult, solve problem, and share information. ${ }^{49}$

\section{DISCUSSION}

\section{Summary}

A total of 27 qualitative studies of HCPs management of older people with depression were systematically reviewed. Decisions regarding the identification and management of depression in later life were underpinned by strong assumptions across all settings that older people were resistant to discussing depression and its treatment; these views were compounded by physical health being prioritised over mental health and a high variation in skills and training among HCPs, particularly for nurses. Beliefs about the causes of depression and its social origins underpinned decisions regarding when and what treatment was appropriate, particularly for GPs, which further depended upon a 'postcode lottery regarding the treatments that were available for consideration.

\section{Strengths and limitations}

Studies were systematically identified and drew on views from a range of professionals, countries, settings, and ethnicities. This provided a more complete picture of how depression is managed in older adults, including in those with frailty or multimorbidity.

A constructivist approach was taken to identify and contrast multiple conceptualisations of late-life depression. Other reviews have focused mainly on GPs, ${ }^{21,52}$ but the one presented here also included the views of nurses and other HCPs. However, it is important to note that most studies were carried out in highincome Western countries and, due to a lack of resources for translation, only English-language studies could be included. One excluded study, reported in German, found themes almost identical to the review presented here..$^{53}$ Although family played a larger role in the studies from Taiwan and India, similar themes were also identified, so the findings presented here may have some transferability to these settings.

Meta-ethnography, which may have offered greater conceptual integration, was not used but the ability to compare across HCPs - as outlined by Barnett-Page and Thomas $^{23}$ - was considered a key advantage for this review. A further strength is that the majority of included studies were of good quality. Theses also provided a richer source of data than published papers but, as it was only possible to access UK theses, it could be that further qualitative evidence exists from other countries.

\section{Comparison with existing literature}

Similar themes of depression being considered a normal response to challenging social circumstances, caution being exercised regarding medicalising social issues, and a lack of psychological therapies have been found in HCPs' views of depression in adults. ${ }^{21,52}$ However, ideas such as 'secondary gains' to a depression diagnosis (for example, avoiding social problems, feelings of powerlessness, or work) or overtly negative attitudes were not discussed regarding late-life depression, ${ }^{21,52}$ possibly as late-life depression was felt to be more justifiable.

Other elements have been discussed elsewhere that were not discussed in this review, including taking a shortterm view for older adults (for example, GPs' reduced concern around addiction to benzodiapezines as people were unlikely to live for much longer ${ }^{54}$ ) and involving family and/or supporting carers in depression management. 55,56

Social workers and family carers expressed similar views around late-life depression, a lack of priority for mental health, and low availability of resources. ${ }^{57,58}$ Poor access to psychological therapy for older adults has also been documented elsewhere; ${ }^{7}$ this may be compounded by ageist views and a lack of trainees in psychological fields who are motivated to work in the sector. ${ }^{59}$

It has also been identified elsewhere 
that older adults normalise depression, although some studies suggested that older people were more likely to raise depression in emotional rather than somatic terms and lacked awareness of psychological treatments, ${ }^{60}$ despite reporting preferences for them over antidepressants. ${ }^{11,12,14}$

\section{Implications for research and practice}

This review suggests that primary care services for older people do not currently prioritise older adults' mental health to the same extent as their physical health, which is compounded by a lack of referral options suitable to older people's needs. Further investment in psychological and social resources is needed to enable mental health in later life to achieve equitable priority with physical health, particularly if older adults are to be encouraged to use psychological services.

UK guidelines recommend planning partnerships between local authorities, the NHS, community organisations, and voluntary-sector providers to improve mental wellbeing and promote independence in older adults. ${ }^{61}$ Examples of successful management identified in this review suggested that staff training and improved links to other services could result in older people being better supported. Within all services, the roles and responsibilities of $\mathrm{HCPs}$ - and nurses in particular - need to be outlined more clearly.

Most GPs whose views were reflected in this review felt that late-life depression was within their remit. Patient views have suggested that some feel that GPs would not be receptive to discussing mood, and that having a person outside of the GP consultation was beneficial. ${ }^{19,62}$

Research into GPs' views of late-life depression has received substantial coverage and replicating this further in highincome countries is likely to be unnecessary. However, as there was a notable paucity of views of psychological therapists or psychiatrists in this review, despite their role in treating late-life depression, this remains an area for further qualitative research.

Internet or bibliotherapy psychological approaches were also rarely discussed, and, although depression in populations with frailty was considered common, fewer solutions were identified for this subpopulation. Further research into effective and equitable treatments for latelife depression is needed.

In conclusion, this systematic review of qualitative studies suggests that depression in later life can be managed in primary care, but needs to be given greater priority to address the complex needs of older adults. Sufficient staff training and clarity of staff roles is also required. Investment in psychological therapies that are suitable for older adults, along with other social referral options, are needed to facilitate the identification and treatment of late-life depression
School for Hygiene and Tropical Medicine; LiLaC Ithe Liverpool and Lancaster Universities Collaboration); and Fuse, the Centre for Translational Research in Public Health la collaboration between Newcastle University, Durham University, Northumbria University, the University of Sunderland, and Teesside University). The views expressed are those of the authors and not necessarily those of the NHS, the NIHR or the Department of Health. The funders had no role in: the study design; data collection, analysis, and interpretation; the writing of the report; or the decision to submit the article for publication.

\section{Ethical approval}

Not applicable.

\section{Provenance}

Freely submitted; externally peer reviewed.

\section{Competing interests}

The authors have declared no competing interests.

\section{Discuss this article}

Contribute and read comments about this article: bjgp.org/letters 


\section{REFERENCES}

1. Rodda J, Walker Z, Carter J. Depression in older adults. BMJ 2011; 343: d5219

2. White J, Zaninotto P, Walters $K$, et al. Severity of depressive symptoms as a predictor of mortality: the English longitudinal study of ageing. Psychol Med 2015; 45(13): 2771-2779.

3. Diniz BS, Butters MA, Albert SM, et al. Late-life depression and risk of vascular dementia and Alzheimer's disease: systematic review and meta-analysis of community-based cohort studies. Br J Psychiatry 2013; 202(5): 329-335.

4. Meeks TW, Vahia IV, Lavretsky H, et al. A tune in 'a minor' can 'b major': a review of epidemiology, illness course, and public health implications of subthreshold depression in older adults. J Affect Disord 2011; 129(1-3): 126-142.

5. Government Office for Science. Future of an Ageing Population. GOS: London, 2016.

6. Dearman SP, Waheed W, Nathoo V, Baldwin RC. Management strategies in geriatric depression by primary care physicians and factors associated with the use of psychiatric services: a naturalistic study. Aging Ment Health 2006; 10(5): 521-524.

7. Walters K, Falcaro M, Freemantle N, et al. Sociodemographic inequalities in the management of depression in adults aged 55 and over: an analysis of English primary care data. Psychol Med 2018; 48(9): 1504-1513.

8. Calati R, Salvina Signorelli M, Balestri M, et al. Antidepressants in elderly: metaregression of double-blind, randomized clinical trials. J Affect Disord 2013; 147(1-3): 1-8.

9. Benraad CE, Kamerman-Celie F, van Munster BC, et al. Geriatric characteristics in randomised controlled trials on antidepressant drugs for older adults: a systematic review. Int J Geriatr Psychiatry 2016; 31(9): 990-1003.

10. Park H, Satoh H, Miki A, et al. Medications associated with falls in older people: systematic review of publications from a recent 5 -year period. Eur J Clin Pharmacol 2015; 71(12): 1429-1440.

11. Landreville $P$, Landry J, Baillargeon $L$, et al. Older adults' acceptance of psychological and pharmacological treatments for depression. J Gerontol B Psychol Sci Soc Sci2001; 56(5): 285-291

12. Gum AM, Areán PA, Hunkeler E, et al. Depression treatment preferences in older primary care patients. Gerontologist 2006; 46(1): 14-22.

13. Dakin EK, Areán P. Patient perspectives on the benefits of psychotherapy for late-life depression. Am J Geriatr Psychiatry 2013; 21(2): 155-163.

14. Byers AL, Areán PA, Yaffe K. Low use of mental health services among older americans with mood and anxiety disorders. Psychiatr Serv 2012; 63(1): 66-72

15. Royal College of Psychiatrists. Report of the second round of the National Audit of Psychological Therapies for anxiety and depression (NAPT) 2013. London: Healthcare Quality Improvement Partnership, 2013

16. Department of Health. How to make IAPT more accessible to older people: a compendium. London: DH, 2013

17. Gould RL, Coulson MC, Howard RJ. Cognitive behavioral therapy for depression in older people: a meta-analysis and meta-regression of randomized controlled trials. J Am Geriatr Soc 2012; 60(10): 1817-1830

18. Murray J, Banerjee S, Byng R, et al. Primary care professionals' perceptions of depression in older people: a qualitative study. Soc Sci Med 2006; 63(5) 1363-1373.

19. Burroughs H, Lovell K, Morley M, et al. 'Justifiable depression': how primary care professionals and patients view late-life depression? A qualitative study. Fam Pract 2006; 23(3): 369-377.

20. Barley EA, Walters P, Tylee A, Murray J. General practitioners' and practice nurses' views and experience of managing depression in coronary heart disease: a qualitative interview study. BMC Fam Pract 2012; 13: 1.

21. McPherson S, Armstrong D. General practitioner management of depression: a systematic review. Qual Health Res 2012; 22(8): 1150-1159.

22. Thomas J, Harden A. Methods for the thematic synthesis of qualitative research in systematic reviews. BMC Med Res Methodol 2008; 8: 45.

23. Barnett-Page E, Thomas J. Methods for the synthesis of qualitative research: a critical review. BMC Med Res Methodol 2009; 9: 59

24. Critical Appraisal Skills Programme. Making sense of evidence about clinical effectiveness: 10 questions to help you make sense of qualitative research. 2010. https://casp-uk.net/wp-content/uploads/2018/03/CASP-QualitativeChecklist-2018 fillable form.pdf laccessed 21 Jan 2019).

25. Campbell R, Pound P, Pope C, et al. Evaluating meta-ethnography: a synthesis of qualitative research on lay experiences of diabetes and diabetes care. Soc Sci Med 2003; 56(4): 671-684.

26. Dixon-Woods M, Shaw RL, Agarwal S, Smith JA. The problem of appraising qualitative research. Qual Saf Health Care 2004: 13(3): 223-225.

27. Wittink MN, Givens JL, Knott KA, et al. Negotiating depression treatment with older adults: primary care providers' perspectives. J Ment Health 2011; 20(5): 429-437.

28. Apesoa-Varano EC, Hinton L, Barker JC, Unützer J. Clinician approaches and strategies for engaging older men in depression care. Am J Geriatr Psychiatry 2010; 18(7): 586-595.

29. Bao Y, Eggman AA, Richardson JE, et al. Practices of depression care in home health care: home health clinician perspectives. Psychiatr Serv 2015; 66(12): 1365-1368.

30. Bao Y, Eggman AA, Richardson JE, Bruce ML. Misalignment between medicare policies and depression care in home health care: home health provider perspectives. Psychiatr Serv 2014; 65(7): 905-910.

31. Dickinson R, Knapp P, House AO, et al. Long-term prescribing of antidepressants in the older population: a qualitative study. Br J Gen Pract 2010; DOI: https://doi.org/10.3399/bjgp10X483913.

32. Gordon $\mathrm{IH}-\mathrm{J}$. The perspectives of older people and GPS on depression in later life and its management: the stories they tell and ways they respond to each other. 2013. http://sure.sunderland.ac.uk/4663/1/Gordon.pdf laccessed 8 Jan 2019).

33. Hassall S, Gill T. Providing care to the elderly with depression: the views of aged care staff. J Psychiatr Ment Health Nurs 2008; 15(1): 17-23.

34. Liebel DV, Powers BA. Home health care nurse perceptions of geriatric depression and disability care management. Gerontologist 2015; 55(3): 448461 .

35. Aakhus E, Oxman AD, Flottorp SA. Determinants of adherence to recommendations for depressed elderly patients in primary care: a multimethods study. Scand J Prim Health Care 2014: 32(4): 170-179.

36. Lin Y-R. The impact of the prospective payment system on psychiatric home health care for depressed older adults [Thesis]. Philadelphia, PA: University of Pennsylvania, 2005

37. Lu LC. Hsieh PL. Frontline healthcare providers' views of depression and its prevention in older adults. J Clin Nurs 2013; 22(11-12): 1663-1671.

38. McCabe MP, Davison T, Mellor D, George K. Barriers to care for depressed older people: perceptions of aged care among medical professionals. Int J Aging Hum Dev 2009; 68(1): 53-64

39. Pusey $\mathrm{H}$. The role of the district nurse in the detection and management of depression in older people [Thesis]. Manchester: University of Manchester, 2009

40. Stanners MN, Barton CA, Shakib S, Winefield HR. A qualitative investigation of the impact of multimorbidity on GP diagnosis and treatment of depression in Australia. Aging Ment Health 2012; 16(8): 1058-1064.

41. Strachan J, Yellowlees G, Quigley A. General practitioners' assessment of, and treatment decisions regarding, common mental disorder in older adults: thematic analysis of interview data. Ageing Soc 2015; 35(1): 150-168.

42. Waterworth S, Arroll B, Raphael D, et al. A qualitative study of nurses' clinical experience in recognising low mood and depression in older patients with multiple long-term conditions. J Clin Nurs 2015; 24(17-18): 2562-2570.

43. Iden KR, Hjorleifsson S, Ruths S. Treatment decisions on antidepressants in nursing homes: a qualitative study. Scand J Prim Health Care 2011; 29(4): 252-256.

44. Patel V, Prince M. Ageing and mental health in a developing country: who cares? Qualitative studies from Goa, India. Psychol Med 2001; 31(1): 29-38.

45. Saarela T, Engeström R. Reported differences in management strategies by primary care physicians and psychiatrists in older patients who are depressed. Int J Geriatr Psychiatry 2003; 18(2): 161-168.

46. White J, Greer K, Russell G, et al. Factors affecting services offered to older adults with psychological morbidity: an exploration of health professional attitudes. Aging Ment Health 2017; 1-8. DOI: 10.1080/13607863.2017.1393797.

47. Liebel DV, Powers BA, Hauenstein EJ. Home health care nurse interactions with homebound geriatric patients with depression and disability. Res Gerontol Nurs 2015; 8(3): 130-139

48. Tai-Seale M, McGuire T, Colenda $\mathrm{C}$, et al. Two-minute mental health care for elderly patients: inside primary care visits. J Am Geriatr Soc 2007; 55(12): 1903-1911. 
49. Sussman T, Yaffe M, McCusker J, et al. Improving the management of late-life depression in primary care: barriers and facilitators. Depress Res Treat 2011 . 2011: 326307

50. Todman JP, Law J, MacDougall A. Attitudes of GPs towards Older Adults Psychology Services in the Scottish Highlands. Rural Remote Health 2011; 11(1): 1496

51. Timson S. Constructions of the older adult with depression: in light of the lower than expected referrals to psychological services [Thesis]. Wolverhampton: University of Wolverhampton; 2013.

52. Barley EA, Murray J, Walters P, Tylee A. Managing depression in primary care: a meta-synthesis of qualitative and quantitative research from the UK to identify barriers and facilitators. BMC Fam Pract 2011; 12: 47.

53. Gühne U, Luppa M, Stein J, et al. ['The Forgotten Patients': Barriers and opportunities for optimized treatment of late life depression]. 'Die vergessenen Patienten': Barrieren und Chancen einer optimierten Behandlung depressiver Erkrankungen im Alter. Psychiat Prax 2016; 43(7): 387-394.

54. Cook JM, Marshall R, Masci C, Coyne JC. Physicians' perspectives on prescribing benzodiazepines for older adults: a qualitative study. J Gen Intern Med 2007; 22(3): 303-307.

55. Farran CJ, Horton-Deutsch SL, Loukissa D, Johnson L. Psychiatric home care of elderly persons with depression: unmet caregiver needs. Home Health Care Serv Q1998; 16(4): 57-73.

56. Hinton L, Sciolla AF, Unützer J, et al. Family-centered depression treatment for older men in primary care: a qualitative study of stakeholder perspectives. BMC Fam Pract 2017; 18(1): 88.

57. McCrae N, Murray J, Banerjee S, et al. 'They're all depressed, aren't they?' A qualitative study of social care workers and depression in older adults. Aging Ment Health 2005; 9(6): 508-516.

58. Mellor D, Davison T, McCabe M, George K. The management of depressed elderly care recipients: family perspectives on the skills of professional carers. $J$ Community Health Nurs 2008; 25(1): 44-61.

59. Lee K, Volans PJ, Gregory N. Trainee clinical psychologists' views on recruitment to work with older people. Ageing Soc 2003; 23(1): 83-97.

60. Corcoran J, Brown E, Davis M, et al. Depression in older adults: a metasynthesis. J Gerontol Soc Work 2013; 56(6): 509-534.

61. National Institute for Health and Care Excellence. Depression in adults: recognition and management. London: NICE, 2009.

62. Overend $\mathrm{K}$, Bosanquet $\mathrm{K}$, Bailey $\mathrm{D}$, et al. Revealing hidden depression in older people: a qualitative study within a randomised controlled trial. BMC Fam Pract 2015; 16: 142 